\title{
Performance evaluation of the novel portable PIMA point-of-care CD4 analyzer in comparison with conventional flow cytometer instruments in Cameroon
}

Bertrand Sagnia ${ }^{*}$, Rachel Kamgaing ${ }^{2}$, Charles Kouanfack ${ }^{3}$, Georgette Kamdem, Samuel Sosso ${ }^{2}$, Edith Temgoua ${ }^{5}$, Zéphyrin Tsomo ${ }^{3}$, Lucille Mabouli Zoa ${ }^{5}$, Charlotte Tangimpundu ${ }^{5}$, Godwin Nchinda ${ }^{1}$ and Alexis Ndjolo ${ }^{1}$

\begin{abstract}
Background: Absolute CD4+ T-lymphocyte counts are used in the initiation and monitoring of antiretroviral therapy in HIV-infected patients: with the increase number of HIV infected patient and the reduce number of heath care system in rural zones, HIV monitoring in resource-constrained settings demands affordable and reliable CD4+ T lymphocytes enumeration methods. We evaluated a simple PIMA POC which is a dedicated system for enumeration that uses immunomagnetic and immunofluorescent technologies. The instrument was designed to be a low-cost, yet reliable and robust one. In this study, we assessed the correlation between most representative flow cytometry instruments present in Cameroon instead of CyFlow from PARTEC, FACSCount, and FACSCalibur both from Becton Dickinson.

Methods: CD4 surface markers on lymphocytes was measured on samples collected in EDTA tubes from 268 patients aged from 1 to 65 years old in three different health care structures. HIV infected patients are coming from CIRCB, Day Hospital of Hopital Central de Yaounde (HCY) and Hopital General de Yaounde (HGY). After inform consent, samples were collected and 101 samples were tested with the FACSCalibur, 60 samples were tested with the CyFlow and 107 samples were tested with the FACSCount flow cytometers. All these samples were tested by different technician with PIMA POC present in all these health care structures and the correlation and agreement were analyzed using linear regression and Bland-Altman analysis.

Results: The PIMA POC system has excellent precision, accuracy and linearity for CD4+ T lymphocytes enumeration. Good correlations were obtained between the PIMA POC system and other single platform methods. Bland-Altman plots showed interchangeability between the three machines. Absolute CD4+ T-lymphocyte values obtained from the PIMA system correlated well with Cyflow, FACSCount, and FACSCalibur method ( $r 2$ varies from 0.88 to $0.968, P<0.0001$ ). The comparison between values obtained from PIMA with CYFLOW, FACSCount, and FACSCalibur give $P=0.17, P=0.5$ and $P=0.6$ respectively meaning that there is not significant differences between values obtained with PIMA and other flow machines.

(Continued on next page)
\end{abstract}

\footnotetext{
* Correspondence: bertrandsagnia@yahoo.fr

'Microbiology and Immunology Laboratory of Chantal BIYA International Reference Centre for Research on Prevention and Management of HIV/AIDS (CIRCB), Yaounde, Cameroon

Full list of author information is available at the end of the article
}

(c) The Author(s). 2020 Open Access This article is licensed under a Creative Commons Attribution 4.0 International License, which permits use, sharing, adaptation, distribution and reproduction in any medium or format, as long as you give appropriate credit to the original author(s) and the source, provide a link to the Creative Commons licence, and indicate if changes were made. The images or other third party material in this article are included in the article's Creative Commons licence, unless indicated otherwise in a credit line to the material. If material is not included in the article's Creative Commons licence and your intended use is not permitted by statutory regulation or exceeds the permitted use, you will need to obtain permission directly from the copyright holder. To view a copy of this licence, visit http://creativecommons.org/licenses/by/4.0/. 
(Continued from previous page)

Conclusion: This POC PIMA system is a simple and reliable system for enumeration of absolute CD4+ T-lymphocytes. Having one PIMA system easy to use, should reduce the cost and thus increase access to CD4 testing for HIV infected patients in resource-constrained countries. POC CD4 may also alleviate testing burdens at traditional central CD4 laboratories, hence improving test access in both rural and urban environments. This will reduce also the loss of follow up.

Keywords: HIV, CD4 T-Lymphocyte, PIMA, Flow cytometry, Cameroon

\section{Background}

An estimated 540,000 adults and children in 2018 are living with HIV in Cameroon according to the UNAIDS in 2018 with an estimated 23.000 newly infected; $52 \%$ of children and adults are under antiretroviral treatment (ART). An ambitious target of the UNAIDS to end the help end the HIV AIDS epidemic was also adopted in Cameroon, as a country with resources limited setting, the slogan of 90-90-90 was not reach because only $74 \%$ of people all ages know their HIV status, $71 \%$ are on treatment. Only 55\% of these patients have got access to biological follow up include the CD4 $\mathrm{T}$ cells testing exam $[1,2]$. These CD4 T cells are cells of our immune system targeted by HIV AIDS. These cells are depleted during the chronic HIV infection if the patient is not under adequate ART. The number of these cells, is a mainstay of monitoring the HIV disease progression and ART. Their monitoring is an integral part of the management of both newly diagnosed and chronically infected HIV patients [3, 4]. Absolute CD4+ T-lymphocyte counts are used in the initiation and monitoring of ART in HIV-infected patients: with the increase number of HIV infected patient and the reduce number of heath care system in rural zones, HIV monitoring in resourceconstrained settings demands affordable and reliable CD4+ $\mathrm{T}$ lymphocytes enumeration methods. CD4+ Lymphocyte counts are routinely ordered during the early phases of ART and for prophylaxis of opportunistic infections in HIV-positive patients [5, 6]. As new POC CD4 technologies become available, their performance should be assessed before his deployment in Cameroon and in Africa where the prevalence of HIV is high and there is a reduce number of conventional flow cytometry CD4 machines [7]. In a resource limited setting, CD4 count facility is not available in peripheral areas and often the patients need to travel long distances or the samples need to be transported to the centre where the facility for CD4 count estimation is available [8]. The HIV management needs the medical doctor or the nurse with the respect of guide lines, the compliance of the patient who is taken drugs, the medical analysis lab with several diagnostic technologies for CD4 T cells, viral load, biochemistry analysis and the drug resistance testing. In this study we assessed the feasibility of use of PIMA POC CD4 analyzer in the field setting in
Cameroon in comparison with CyFlow from PARTEC, FACSCount, and FACSCalibur both from Becton Dickinson. This PIMA POC is a dedicated system for enumeration that uses immunomagnetic and immunofluorescent technologies with the closed disposable cartridge containing the reagents required for the CD4+ $\mathrm{T}$ cell count estimation. The instrument was designed to be a low-cost, yet reliable and robust one. In different countries such as Kenya, Zimbabwe, South Africa and Uganda where the evaluation was done, it's shown that the PIMA analyzer could give CD4 counts comparable to those obtained with the standard flow cytometers such as FACSCount and FACSCalibur [9-14]. In respectful of the quality assurance procedures, the introduction of a new plate form needs an evaluation in terms of performance comparison and correlation with other plate forms present in the country. This will significantly improve patient management instead of care, treatment and clinical decision making [15]. The PIMA POC technology was for resources limited setting, to improve the quality of patient care, to increase the level of access to the diagnosis lab, the antiretroviral treatment in laboratory infrastructure, to facilitate HIV prevention through early detection and treatment, to decentralize the access [16].

There are a number of potential advantages to using the POC in such settings: (i) CD4 results are rapidly available enabling the early identification and management of patients with low CD4 counts, (ii) use of POC may aid the assessment of newly diagnosed patients and avoid the need for a repeat clinic visit and (iii) it is independent of laboratory logistics offering the ability to undertake testing in a variety of settings. Potential disadvantages include: (i) the need for a skilled healthcare worker to carry out the test, (ii) there are implications for service provision including training, quality assurance and the patient pathway in clinic and (iii) the PIMA POC does not currently provide a CD4 percentage [17].

\section{Material and methods}

\section{Ethical review}

The Cameroon National Ethics Committee approved the protocol prior to implementation with the number 2011/12/454/L/CNERH/SP. Blood samples were collected in the context of routine CD4 count testing for patients at CIRCB and other health facilities. Written 
informed consent is not required for receipt of routine services including $\mathrm{CD} 4$ testing performed at $\mathrm{MOH}$ facilities. Residual blood from routine testing was used for the analysis. No personally identifiable information was made available to the researchers. The institutional review boards waived the need for written informed consent.

\section{Study setting}

This study was done in three health facilities offering CD4+ $\mathrm{T}$ cell enumeration: Chantal BIYA International Reference Centre with PIMA and FACSCalibur flow cytometer, Central Hospital of Yaounde with PIMA and CyFlow, and General Hospital of Yaounde with PIMA and FACSCount flow cytometer. The sites used different testing platforms (BD FACSCount ${ }^{\mathrm{mi}}$, PARTEC Cyflow ${ }^{\mathrm{rm}}$, and BD FACSCalibur $\left.{ }^{\mathrm{rm}}\right)$ for routine $\mathrm{CD} 4+\mathrm{T}$ enumeration.

\section{Study participants}

A total of 260 were recruited from the three study sites. Data on gender and age were available for all the patients. $56 \%$ were female while $44 \%$ were male. The median age was 36 years (range $1-65$ years old) with an approximately normal distribution; 68 patients were aged 18 years or less. At least $37.7 \%$ of the patients were on antiretroviral therapy. Qualified and trained laboratory technicians conducted all tests.

\section{Study design}

In this methods comparison study, venous blood specimens were collected consecutively from all eligible patients presenting at the health infrastructures included in the study who agreed to participate in the study through informed consent. Demographic data, CD4+ T cell count, and date of clinic visit were all recorded in a structured questionnaire and entered into a constructed database. This study was reviewed and approved by the National Ethical Review Committee. Patients were only provided with $\mathrm{CD} 4+\mathrm{T}$ cell results obtained from the conventional $\mathrm{CD} 4$ testing platforms for further clinical management.

\section{Laboratory procedures}

CD4 testing using each of the available devices was done according to manufacturers' instructions. Whole blood collected in EDTA tubes was used for the BD FACS Count $^{\mathrm{mm}}$, the BD FACSCalibur ${ }^{\mathrm{mix}}$, the PARTEC Cyflow ${ }^{\mathrm{m}}$, and the Alere PIMA device. The Alere PIMA was present in all the three sites. Both internal quality assurance (IQA) were implemented for the platforms according to manufacturers' instructions and existing individual laboratory protocols. During the study, we received samples for external quality control from QASI in Canada. Facility flow cytometers in the sites are enrolled in one External
Quality Assurance Schemes. The CIRCB, was enrolled in the UKNEQAS EQA program. Control cartridges (both high and low) were run on the PIMA devices every morning before tests. PIMA devices reporting errors were not used for this work.

\section{PIMA procedure}

Twenty-five microliters of the blood sample was dispensed into a disposable anticoagulant-coated cartridge preloaded with antihuman $\mathrm{CD} 3$ and $\mathrm{CD} 4$ monoclonal antibodies conjugated with fluorescent labels (excitation at $520 \mathrm{~nm}$, emission at $671 \mathrm{~nm}$ and $575 \mathrm{~nm}$, respectively). The cartridge was capped and inserted immediately into the analyzer and the test performed. During the 20-min analysis process, the blood sample was mixed with the freeze-dried fluorescently conjugated monoclonal antibodies present within the cartridge. A series of images of the fluorescent labeled cells in the fixed volume detection chamber were collected and the data analyzed for the absolute number of CD3 + CD4+ Tlymphocytes [13, 14, 17-19].

\section{FACSCalibur procedure}

Fifty microliters of whole blood was dispensed in a TruCount tube containing $20 \mu \mathrm{l}$ of BD Multitest fluorescent conjugated monoclonal antibodies, and vortexed for $5 \mathrm{~s}$. The Multitest consists of CD3-FITC/CD8-PE/CD45PerCP/CD4 APC reagent. The mixture was incubated for $15 \mathrm{~min}$ at room temperature in the dark before adding $450 \mu \mathrm{l}$ of FACS ${ }^{\mathrm{Tm}}$ lysing solution and incubating for an additional $15 \mathrm{~min}$ in the dark prior to acquisition on the FACSCalibur. Data were analyzed using the MultiSET $^{\text {TM }}$ software with automated gating and analysis. In this analysis, CD3 $\mathrm{T}$ lymphocytes, CD3CD4 $\mathrm{T}$ cells and $\mathrm{CD} 3 \mathrm{CD} 8 \mathrm{~T}$ cells in absolute and relative values were determined, and the ratio CD4/CD8. Only the CD3CD4 T cells were used for comparison with PIMA [20].

\section{FACSCount procedure}

Fifty microliter of uncoagulated whole blood was added to the $\mathrm{CD} 4 / \mathrm{CD} 3$ reagent tube (containing monoclonal antibodies and known number of microbeads) using an electronic pipette (BDB). The tube was vortexed for $5 \mathrm{~s}$ and incubated in the dark at room temperature for $60 \mathrm{~min}$. Then, $50 \mu \mathrm{l}$ of a fixative solution $(5 \%$ of formaldehyde in PBS) provided with the reagent kit was added to the tube. The tube was vortexed, and the non lysed stained sample was analyzed in FACSCount FCM using an automated FACSCount software. After acquisition of 30,000 events for each sample, the gate was set up automatically around $\mathrm{CD} 3+/ \mathrm{CD} 4+\mathrm{T}$ lymphocytes [21]. 


\section{CyFlow method}

Twenty microliters of whole blood were added into a sample tube (on top of the lyophilized antibody spot at the bottom of the tube) gently mixed and incubated for $15 \mathrm{~min}$ (mix again after $5 \mathrm{~min}$ ) in the dark at room temperature. Then, Buffer 1 was poured and mixed, and the Buffer 2 was added directly prior to the measurement on the CyFlow miniPOC. Stained blood was completely aspirated with a new syringe until the plunger reaches the position $1 \mathrm{ml}$ (avoid having air bubble in the extremity of the syringe). The syringe was attached to the device, analysis started and the results (CD4 count and $\mathrm{CD} 4 \%)$ were available in less than $2 \min [19,22]$.

\section{Data analysis}

The results of the evaluation were analyzed using standard statistical methods. The absolute CD4+ T Cell counts derived from Alere PIMA device were compared with those derived from existing technologies by calculating the coefficient of determination (r2) and conducting regression analysis using XLSTAT. To determine interchangeability between the device and existing platforms, Bland-Altman analysis was used. For the former analysis, the bias was defined as the mean difference between two methods. Confidence intervals for bias and for limits of agreement were calculated using formulae previously described by Bland and Altman. The $\mathrm{x}$ axis on each Bland-Altman plot was the average value of the two methods while the $y$ axis was the difference between the two methods.

\section{Results}

A total of 260 patients were enrolled in the study, of which $68.4 \%$ were women. The median age of the study population was 34 years (range 1-65). The comparison of CD4 count from 101 samples was done between FACSCalibur and PIMA, 60 samples between CyFlow and PIMA and finally on 107 samples between FACS Count and PIMA. Table 1 shows the characteristics of summary of different CD4 enumeration techniques and the place of manipulation. Table 2 shows the comparison between the CD4 results by instrument compared with PIMA. The coef of Pearson correlation of all those CD4 counts are $0.972,0.947$, and 0.948 for FACSCalibur and PIMA, FACSCount and PIMA and CyFlow with PIMA. In this study, the FACScalibur is the reference instrument respectively. We could observe that the number of CD4 machine has to be increased to facilitate the management of all those patients on treatment, those to initiate the treatment. The Fig. 1 shows the linear regression analysis and Bland-Altman analysis using whole blood. In this study, we have repeated ten samples and the correlation was very high (personnel data).

\section{Discussion}

The abstract of this study was presented as oral presentation at ICASA 2011 at Addis Ababa in Ethiopia. The results from the comparisons between PIMA and FACS Calibur as a reference flow machine, the FACSCount and the Cyflow indicate that PIMA gives similar results as found in other studies $[14,19]$. Comparing the different threshold, PIMA tended to underestimate the CD4 counts at higher $\mathrm{CD} 4$ counts $(>350$ cells $/ \mathrm{mL})$. The underestimation of the absolute $\mathrm{CD} 4$ counts was relatively smaller at lower CD4 ranges and disappeared for CD4 cell counts of, $<200 \mathrm{CD} 4+\mathrm{T}$ cells per microliter. This means that when PIMA is used as a screening tool

Table 1 Summary of characteristics of various CD4+ T cells enumeration techniques

\begin{tabular}{|c|c|c|c|c|}
\hline \multirow[t]{2}{*}{ Parameter } & \multicolumn{4}{|c|}{ Dedicated technology based assay } \\
\hline & FACSCalibur & FACSCount & CyFlow & PIMA \\
\hline Manufacturer & Becton Dickinson (CA, USA) & Becton Dickinson (CA, USA) & $\begin{array}{l}\text { Partec GmbH } \\
\text { (Munster,Germany) }\end{array}$ & Alere Medical Pvt. Ltd., USA \\
\hline Platform & TruCount & $\begin{array}{l}\text { Dedicated CD4/CD4\% } \\
\text { counter }\end{array}$ & Dedicated CD4 Count & Dedicated CD4 Count \\
\hline Principle & Flow cytometry & Flow cytometry & Flow cytometry & Flow cytometry \\
\hline Monoclonal antibodies used & Multitest CD3/CD8/CD45/CD4 & Anti-CD4 \&anti CD3 & Anti-CD3, anti-CD4 & Anti-CD3, anti-CD4 \\
\hline Cost per test (US\$) & 30 & 25 & 12 & 10 \\
\hline Cost of the instrument (US\$) & 75,000 & 30,000 & 22,000 & 12,000 \\
\hline Specimen type & whole blood & whole blood & whole blood & whole blood \\
\hline specimen volume $(\mu \mathrm{L})$ & 50 & 50 & 50 & 25 \\
\hline Technique & Lyse no wash & No lyse No wash & No lyse No wash & No lyse No wash \\
\hline Gating strategy & CD45/SSC & CD3/SSC & partec gating & CD3 \\
\hline Structure & CIRCB (a) & GHY (b) & Day Hospital CHY@ & $\mathrm{CIRCB}, \mathrm{GHY}, \mathrm{CHY}$ \\
\hline
\end{tabular}

(a) “Chantal BIYA International Reference Centre for Research on Prevention and Management of HIV/AIDS (CIRCB)

(b) General Hospital of Yaounde

c Day Hospital Central Hospital of Yaounde (CHY) 
Table 2 Median of absolute CD4+ T lymphocyte count in all blood samples and the absolute CD4+T - Lymphocyte count range of 0-350 and greater than 350cell/ $\mu \mathrm{L}$ determine by the PIMA and other predicate flow cytometry systems

\begin{tabular}{|c|c|c|c|c|c|}
\hline \multirow[t]{5}{*}{ A } & \multirow[t]{2}{*}{ Absolute CD4+T Lymphocyte counts } & \multirow[t]{2}{*}{ Number } & \multicolumn{2}{|l|}{ Median (range) } & \multirow[t]{2}{*}{ Pearson correlation } \\
\hline & & & PIMA System & FACSCalibur & \\
\hline & All & 101 & $405(12-2058$ & $398(3-2276)$ & 0,972 \\
\hline & $0-350$ & 39 & 189(12-419) & $206(3-334)$ & \\
\hline & $>350$ & 62 & $505(405-2058)$ & $543(354-2276)$ & \\
\hline \multirow[t]{5}{*}{ B } & \multirow[t]{2}{*}{ Absolute CD4+ T lymphocyte counts } & \multirow[t]{2}{*}{ Number } & Median (range) & & \multirow[t]{2}{*}{ Pearson correlation } \\
\hline & & & PIMA System & FACSCount & \\
\hline & All & 107 & $421(17-1128)$ & $362(4-899)$ & 0,949 \\
\hline & $0-350$ & 50 & $223(17-606)$ & $190(4-344)$ & \\
\hline & $>350$ & 57 & $540(363-1128)$ & $501(354-899)$ & \\
\hline \multirow[t]{5}{*}{$C$} & \multirow[t]{2}{*}{ Absolute CD4+ T lymphocyte counts } & \multirow[t]{2}{*}{ Number } & Median (range) & & \multirow[t]{2}{*}{ Pearson correlation } \\
\hline & & & PIMA System & CyFlow & \\
\hline & All & 60 & $379(12-1167)$ & $369(6-1016)$ & \multirow[t]{3}{*}{0,945} \\
\hline & $0-350$ & 26 & $226(12-347)$ & $223(6-373)$ & \\
\hline & $>350$ & 34 & 488(351-1167) & 443(263-1016) & \\
\hline
\end{tabular}

to identify patients eligible for ART with cut-offs of 200 or $350 \mathrm{CD} 4+\mathrm{T}$ cells per microliter, results are sufficiently accurate to avoid significant misclassification of patients. The instrument showed a remarkably good agreement with the three instruments for values $<200$ CD $4+\mathrm{T}$ cells $/ \mu \mathrm{L}$, for venous blood. This is important for reliable screening of patients at the point-of-care in resource-limited countries as the 200 CD4 cell cut-off is still frequently used in these setting to initiate treatment. Taking into account the new 2010 WHO guidelines recommending a cut-off of 350 instead of $200 \mathrm{CD} 4+\mathrm{T}$ cells $/ \mu \mathrm{L}$ to initiate treatment, the "clinical" agreement between both instruments was still acceptable. Indeed, PIMA's sensitivity for identifying patients eligible for treatment was still 98\% for venous samples, despite lower specificities of $79 \%$. This would be acceptable from the patient's perspective, as several patients would receive treatment slightly earlier than scheduled (at 250300 CD4+ T cells per microliter instead of at, 200). From the treatment program's perspective, however, this would increase the total cost of treatment as more people would be treated than strictly required. At high CD4+ T-cell counts, which are more relevant for monitoring immune reconstitution during treatment, measurement precision using venous blood was consistently good. The strengths of this instrument are its small size, its affordability, its ease of use at the point-of-care, and the small blood volume required per analysis. It is considerable less expensive than flow cytometry-based instruments. The fact that the cartridges contain all required reagents, ready-to-use, without the need for delicate pipetting (finger-prick blood) is an asset as less training of staff is required. Blood sampling by finger prick or heel prick would offer several other advantages, for pediatric cases in particular, because it is less invasive and requires a very small blood sample per test. Unfortunately, the instrument does not measure CD4 percentages yet which is preferred over absolute counts in pediatric HIV cases. Therefore, once blood has been inserted in the cartridges, it must be processed immediately by the instrument. The choice of an instrument like the PIMA would be primarily determined by the type of setting and by the available resources. The entire process from incubation to reading and printing of results takes place inside the PIMA analyzer, and monopolizes the instrument. Therefore, the sample throughput is relatively low, with for instance 1 sample every $20 \mathrm{~min}$ or even longer, including preparation time. This restriction could be lifted by installing 2 or more instruments per site and running multiple analyses in parallel. Another restriction is that once cassettes are loaded with blood, they should be analyzed immediately by the instrument. This means that patients can only give fingerprick blood when an instrument is available. The use of anticoagulated venous blood overcomes this restriction, but the instrument is intended to be used with capillary blood. Instruments like the PIMA would be of interest to health care workers who are looking for a very simple and affordable instrument to test a limited number of samples per day at the point-of-care. Patients can wait until the results are ready to discuss treatment, if required. Furthermore and not unimportant, patients do not need to return to the clinic just to be informed about the results of the test, decreasing the risk of being lost to follow-up [23]. Finally, this instrument has demonstrated a good performance under field conditions. 

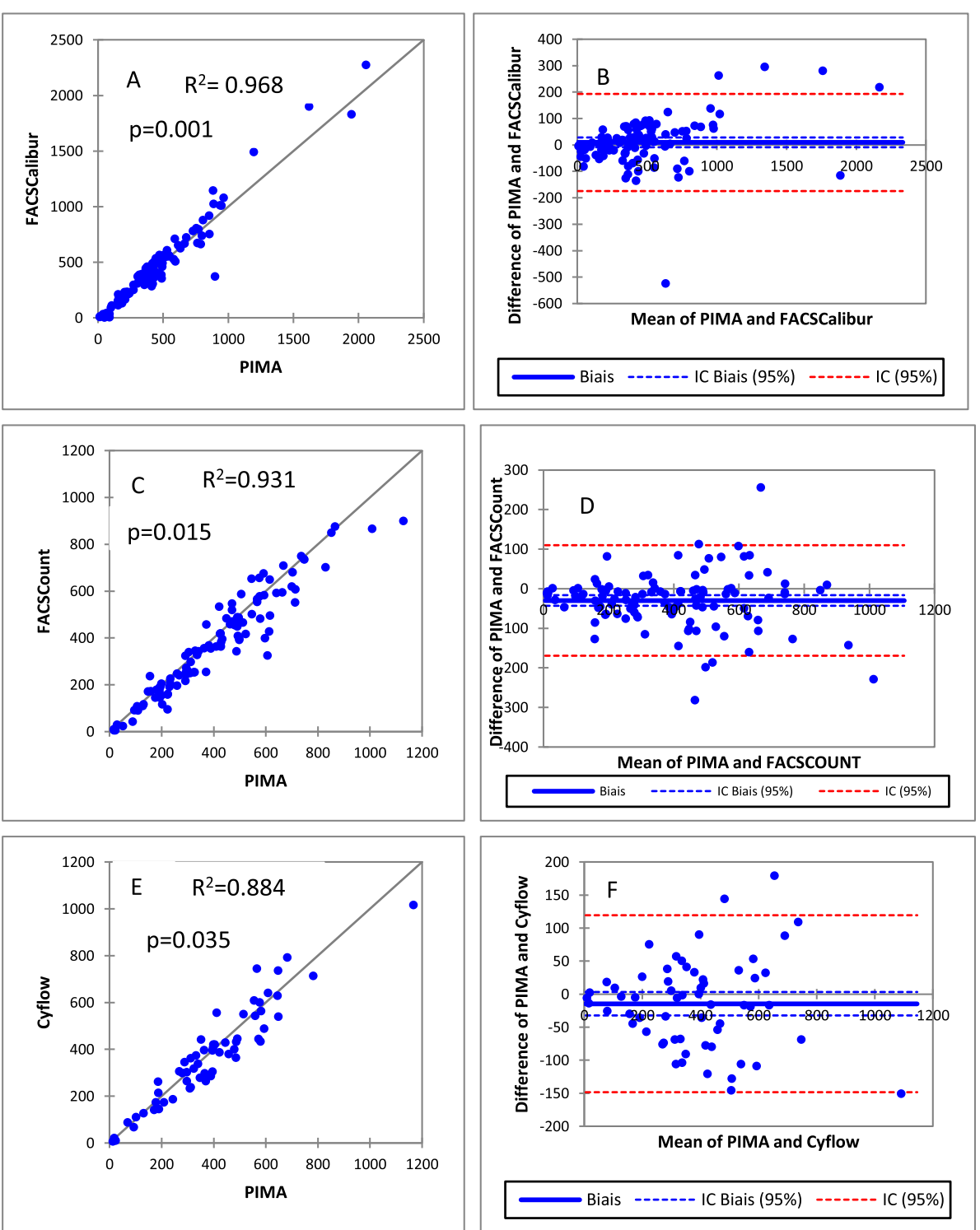

Fig. 1 Linear regression analysis and Bland-Altman analysis using whole blood sample of absolute CD4+ T lymphocyte counts between PIMA and FACSCalibur (a and $\mathbf{b}$ ), PIMA and FACSCount ( $\mathbf{c}$ and $\mathbf{d}$ ), and PIMA and CyFlow (e and $\mathbf{f}$ ) respectively

This could be to the benefit of patients in resourcelimited settings as it can help clinicians screen patients for treatment eligibility at the point of-care. CD4 test is done in Cameroon at the beginning of the ART, 6 weeks after partum, 6 months after postpartum and after 24 months [24]. In the scale up of viral load as a follow up marker of the HIV infection, the CD4 count continue to be important to evaluate the immune system of the patient. Viral load and CD4 are important in the interpretation of the resistance test to associate the virology or and the immunologic failure of the ART.

Delays in CD4 count testing and return of results are a barrier in the cascade from learning HIV positive results to initiating ART. In a study from a South African clinic,
$75 \%$ of newly identified HIV positive persons who had CD4 testing did not return in 12 weeks for results or ART referral. Point-of-care (POC) CD4 tests, with immediately available results, would increase engagement in care but require evaluation.

\section{Conclusion}

The high performance of the PIMA point-of-care test methodology suggest its utility as an alternative method for rapid measurement of $\mathrm{CD}_{4}^{+} \mathrm{T}$ lymphocyte in patients in remote areas in developing countries, enabling prompt therapeutic intervention for patients at risk of progression to AIDS. Compared against the gold standard of flow cytometry for CD4 testing the PIMA POC 
CD4 test, when done in a field setting, provides a highly comparable result and can be used to guide ART initiation. It's well know that delays in CD4 count testing and return of results are a barrier in the cascade from learning HIV results to initiate ART. Field performance of POC CD4 testing should be evaluated as a way to increase linkages to HIV care, particularly in resourceconstrained settings.

\section{Abbreviations}

ART: Anti-Retroviral Therapy; AIDS: Acquired immunodeficiency syndrome; CIRCB: Chantal BIYA International Reference Centre for Research on Prevention and Management of HIV/AIDS (CIRCB).; EQA: External Quality Assurance; HCY: Hopital Central de Yaounde; HGY: Hopital General de Yaounde; HIV: Human Immunodeficiency Virus; IQA: Internal Quality Assessment; POC: Point Of Care; QASI: Quality Assessment and Standardization of Indicators relevant to HIV/AIDS; UKNEQAS: United Kingdom of National Quality Assessment Site

\section{Acknowledgements}

We would like to thank patients in all health care structures to have accepted to participate to the study. We wish to acknowledge Irenée DOMKAM for statistical advice.

\section{Authors' contributions}

SB conceived and designed the study with KR, KC and KG. TE and SM, drafted the manuscript and analysed the data with TC and ML. SB, KC, and TZ formatted the figure, tables and the article. NG and NA reviewed the data. All authors read and approved the final manuscript.

\section{Funding}

No funds were available to sustain this study.

\section{Availability of data and materials}

The data supporting the conclusions of this article are included within the article.

\section{Ethics approval and consent to participate}

This study was approved by the National Ethics Committee. Informed consent was obtained from all participants included in the study.

\section{Consent for publication}

The manuscript is approved by all authors for publication. This article does not contain any individual person's data in any form.

\section{Competing interests}

The authors declare that they have no competing interests.

\begin{abstract}
Author details
${ }^{1}$ Microbiology and Immunology Laboratory of Chantal BIYA International Reference Centre for Research on Prevention and Management of HIV/AIDS (CIRCB), Yaounde, Cameroon. ${ }^{2}$ Medical Analysis Laboratory of Chantal BIYA International Reference Centre for Research on Prevention and Management of HIV/AIDS (CIRCB), Yaounde, Cameroon. ${ }^{3}$ Day Hospital of Hôpital Central de Yaoundé (HCY), Yaounde, Cameroon. ${ }^{4}$ Medical Analysis Laboratory of Hopital Général de Yaoundé (HGY), Yaounde, Cameroon. ${ }^{5}$ Unités Techniques Médicales of Chantal BIYA International Reference Centre for Research on Prevention and Management of HIV/AIDS (CIRCB), Yaounde, Cameroon.
\end{abstract}

Received: 10 September 2020 Accepted: 15 October 2020

Published online: 04 November 2020

\section{References}

1. UPDATE UGA. COMMUNITIES AT THE CENTRE: DEFENDING RIGHTS BREAKING BARRIERS REACHING PEOPLE WITH HIV SERVICES; 2019.

2. CNLS: Bulletin de Surveillance Epidémiologique Trimestriel. www.cnls.cm 2018, 001-18(01).

3. OMS: Antiretroviral Therapy for HIV Infection in Adults and Adolescents: Recommendations for a Public Health Approach. WHO. 2010. 2010.
4. Phillips AN, Pillay D, Miners AH, Bennett DE, Gilks CF, Lundgren JD. Outcomes from monitoring of patients on antiretroviral therapy in resourcelimited settings with viral load, CD4 cell count, or clinical observation alone: a computer simulation model. Lancet. 2008:371(9622):1443-51.

5. Indira P, Kumar PM, Shalini S, Vaman K. Opportunistic infections among people living with HIV (PLHIV) with diabetes mellitus (DM) attending a tertiary Care Hospital in Coastal City of South India. PLoS One. 2015;10(8): e0136280.

6. Rathunde L, Kussen GM, Beltrame MP, Dalla Costa LM, Raboni SM. Evaluation of the Alere Pima for CD4+ T lymphocytes counts in HIV-positive outpatients in southern Brazil. Int J STD AIDS. 2014;25(13):956-9.

7. Pham MD, Agius PA, Romero L, McGlynn P, Anderson D, Crowe SM, Luchters S. Performance of point-of-care CD4 testing technologies in resource-constrained settings: a systematic review and meta-analysis. BMC Infect Dis. 2016;16(1):592

8. Thakar M, Mahajan B, Shaikh N, Bagwan S, Sane S, Kabra S, Rewari B, Shaukat M, Singh N, Trevor P, et al. Utility of the point of care CD4 analyzer, PIMA, to enumerate CD4 counts in the field settings in India. AIDS Res Ther. 2012;9(1):26.

9. Namuniina A, Lutwama F, Biribawa VM, Kizza D, Kabuubi BR, Kitandwe PK, Mpendo J, Nanvubya A, Ssempiira J, Nalutaaya A, et al. Field performance of PIMA point-of-care machine for CD4 enumeration under a Mobile HIV counseling and testing program in remote fishing Communities of Lake Victoria, Uganda. AIDS Res Hum Retrovir. 2019;35(4):382-7.

10. Zeh C, Rose CE, Inzaule S, Desai MA, Otieno F, Humwa F, Akoth B, Omolo P, Chen RT, Kebede Y, et al. Laboratory-based performance evaluation of PIMA CD4+ T-lymphocyte count point-of-care by lay-counselors in Kenya. J Immunol Methods. 2017:448:44-50.

11. Mtapuri-Zinyowera S, Chiyaka ET, Mushayi W, Musuka G, Naluyinda-Kitabire F, Mushavi A, Chikwasha V. PIMA point of care CD4+ cell count Machines in Remote MNCH settings: lessons learned from seven districts in Zimbabwe. Infect Dis. 2013;6:51-60.

12. Mtapuri-Zinyowera S, Chideme M, Mangwanya D, Mugurungi O, Gudukeya S, Hatzold K, Mangwiro A, Bhattacharya G, Lehe J, Peter T. Evaluation of the PIMA point-of-care CD4 analyzer in VCT clinics in Zimbabwe. J Acquir Immune Defic Syndr. 2010;55(1):1-7.

13. Sukapirom K, Onlamoon N, Thepthai C, Polsrila K, Tassaneetrithep B, Pattanapanyasat K. Performance evaluation of the Alere PIMA CD4 test for monitoring HIV-infected individuals in resource-constrained settings. J Acquir Immune Defic Syndr. 2011;58(2):141-7.

14. Diaw PA, Daneau G, Coly AA, Ndiaye BP, Wade D, Camara M, Mboup S, Kestens L, Dieye TN. Multisite evaluation of a point-of-care instrument for CD4(+) T-cell enumeration using venous and finger-prick blood: the PIMA CD4. J Acquir Immune Defic Syndr. 2011;58(4):e103-11.

15. Lamp K, McGovern S, Fong Y, Abere B, Kebede A, Ayana G, Mulugeta A, Atem CD, Elat Nfetam JB, Nzuobontane D, et al. Point-of-care CD4 technology invalid result rates in public health care settings across five countries. PLoS One. 2019;14(7):e0219021.

16. Haleyur Giri Setty MK, Hewlett IK. Point of Care Technologies for HIV. AIDS Res Treatment. 2014;2014:497046.

17. Herbert S, Edwards S, Carrick G, Copas A, Sandford C, Amphlett M, Benn P. Evaluation of PIMA point-of-care CD4 testing in a large UK HIV service. Sex Transm Infect. 2012;88(6):413-7.

18. Pattanapanyasat K, Phuang-Ngern Y, Sukapirom K, Lerdwana S, Thepthai C, Tassaneetrithep B. Comparison of 5 flow cytometric immunophenotyping systems for absolute CD4+ T-lymphocyte counts in HIV-1-infected patients living in resource-limited settings. J Acquir Immune Defic Syndr. 2008:49(4): 339-47.

19. Dieye TN, Diaw PA, Daneau G, Wade D, Sylla Niang M, Camara M, Diallo AA, Toure Kane C, Diop Ndiaye H, Mbengue B, et al. Evaluation of a flow cytometry method for CD4 T cell enumeration based on volumetric primary CD4 gating using thermoresistant reagents. J Immunol Methods. 2011; 372(1-2):7-13.

20. Pattanapanyasat K, Chimma P, Sratongno P, Lerdwana S. CD4+ Tlymphocyte enumeration with a flow-rate based method in three flow cytometers with different years in service. Cytometry B Clin Cytom. 2008; 74(5):310-8.

21. Pattanapanyasat K, Sukapirom K, Kowawisatsut L, Thepthai C. New BD FACS Count CD4 reagent system for simultaneous enumeration of percent and absolute CD4 T-lymphocytes in HIV-1-infected pediatric patients. Cytometry B Clin Cytom. 2008;74(Suppl 1):S98-106. 
22. Fryland $M$, Chaillet $P$, Zachariah $R$, Barnaba A, Bonte L, Andereassen $R$, Charrondiere S, Teck R, Didakus O. The Partec CyFlow counter could provide an option for CD4+ T-cell monitoring in the context of scaling-up antiretroviral treatment at the district level in Malawi. Trans R Soc Trop Med Hyg. 2006;100(10):980-5.

23. Bekolo CE, Webster J, Batenganya M, Sume GE, Kollo B. Trends in mortality and loss to follow-up in HIV care at the Nkongsamba regional hospital, Cameroon. BMC Res Notes. 2013;6:512.

24. CNLS. DIRECTIVES NATIONALES DE PREVENTION ET DE PRISE EN CHARGE DU VIH AU CAMEROUN; 2014. p. 147.

\section{Publisher's Note}

Springer Nature remains neutral with regard to jurisdictional claims in published maps and institutional affiliations.

Ready to submit your research? Choose BMC and benefit from:

- fast, convenient online submission

- thorough peer review by experienced researchers in your field

- rapid publication on acceptance

- support for research data, including large and complex data types

- gold Open Access which fosters wider collaboration and increased citations

- maximum visibility for your research: over $100 \mathrm{M}$ website views per year

At BMC, research is always in progress.

Learn more biomedcentral.com/submissions 